\title{
Hyperkalemia in chronic kidney disease
}

\section{SUMMARY}

Hyperkalemia is a frequent finding in patients with chronic kidney disease (CKD). This increase in serum potassium levels is associated with decreased renal ion excretion, as well as the use of medications to reduce the progression of CKD or to control associated diseases such as diabetes mellitus and heart failure. Hyperkalemia increases the risk of cardiac arrhythmia episodes and sudden death. Thus, the control of potassium elevation is essential for reducing the mortality rate in this population. Initially, the management of hyperkalemia includes orientation of low potassium diets and monitoring of patients' adherence to this procedure. It is also important to know the medications in use and the presence of comorbidities to guide dose reduction or even temporary withdrawal of any of the potassium retention-related drugs. And finally, the use of potassium binders is indicated in both acute episodes and chronic hyperkalemia.

Keywords: Chronic renal disease. Hyperkalemia. Renin-angiotensin-aldosterone system inhibitors. Calcium polystyrene sulfonate. Partomer. Sodium zirconium cyclosilicate.

\section{INTRODUCTION}

Potassium is the ion most present in body fluids, and approximately $98 \%$ of its concentration is intracellular. The main physiological functions of the ion are to adjust the cellular metabolism, such as the protein and glycogen synthesis, and the basic acid balance. In addition, the difference in potassium concentration intra and extracellular creates a transmembrane potential that is responsible for neuromuscular function'. The serum level of potassium is maintained by the daily excretion of a quantity close to that ingested, approximately $100 \mathrm{mEq} /$ day. The elimination of the ion occurs through the skin, gastrointestinal tract, and kidneys. Normally, the potassium excretion through sweat is approximately $5 \mathrm{mEq} /$ day, in stool between 5 to $10 \mathrm{mEq} /$ day, and in urine around $92 \mathrm{mEq} /$ day. The main mechanism by which the kidney maintains the homeostasis of potassium is by secreting the ion through the distal convoluted tubule and the proximal collecting duct ${ }^{1.2}$.
Hyperkalemia is one of the most important metabolic complications because it can cause electrophysiological disorders with severe clinical repercussions that may lead to death ${ }^{3.4}$. This electrolytic change is defined as the elevation in the serum level of potassium above the range of normality. The mechanisms that lead to hyperkalemia typically involve a combination of factors, such as the increase in the intake of foods rich in potassium, disorderly distribution between the intra and extracellular compartments, and abnormalities in potassium excretion. Chronic kidney disease (CKD) is the most common predisposing condition for an increased level of potassium ${ }^{4.5}$.

The incidence of hyperkalemia varies between $2-35 \%$ of CKD patients, depending on the rate of glomerular filtration rate (GFR) of the population studied, the potassium level considered high by researchers in different studies, the use of inhibitors of the renin-angiotensin-aldosterone system (RAAS) and of 
potassium-sparing diuretics, in addition to the presence of comorbidities, such as diabetes and heart failure ${ }^{6}$. Studies have shown that patients with CKD associated with diabetes mellitus and/or heart failure have a greater risk of developing this metabolic alteration. A decrease in the renal excretion of potassium in combination with one or more exacerbating factors, such as hyperglycemia, insulin deficiency, hyporeninemic hypoaldosteronism, and the use of inhibitors of the RAAS, may induce recurrent episodes of hyperkalemia ${ }^{7.8}$.

A high level of this ion has been associated with increased mortality in the general population and in CKD patients, in its different stages, which highlights the importance of maintaining the serum levels of potassium in the normal range $\mathrm{e}^{7-9}$. This review summarizes the mechanisms that lead to hyperkalemia, its clinical consequences and treatments, with a focus on CKD patients.

\section{MECHANISMS OF HYPERKALEMIA IN CKD}

With the progression of CKD, potassium excretion is decreased, and, in this condition, the intake of foods rich in potassium contributes significantly to the difficulty of maintaining the ion in the normal range. Metabolic acidosis, commonly found in this population, causes the ion to exit the intracellular space to the extracellular, leading to an increase of serum potassium. In renal-transplant patients, acidosis, as well as the use of calcineurin inhibitors, are associated with the occurrence of hyperkalemia ${ }^{10}$.

Some comorbidities, often found in CKD patients, may lead to increased serum levels of the ion. Acute kidney injury results in a rapid decrease in GFR and tubular flow and, usually, is accompanied by a hypercatabolic state, tissue injury, and high levels of potassium (for example, secondary to bleeding). In addition, the acute elevation of the ion can also occur after a blood transfusion. These conditions contribute to the elevation of the serum level of potassium, which may present a risk to the patient's life and is one of the most common indications for emergency dialysis treatment ${ }^{10}$. Diabetes mellitus and cardiovascular disease are two of the most common comorbidities in CKD patients, and both are related to the development of hyperkalemia through different mechanisms. Insulin deficiency and hypertonicity caused by hyperglycemia in patients with diabetes contribute to the reduction of potassium transport to the intracellular space. In addition, diabetes mellitus is associated with hyponatremia hypoaldosteronism and the resulting inability to regulate the tubular secretion of potassium ${ }^{4.10}$.

Cardiovascular diseases, such as hypertension, acute myocardial infarction, left ventricular hypertrophy, and congestive heart failure, require drugs that can lead to hyperkalemia. These drugs, such as cardiac glycosides, contribute to the increase of serum potassium due to inhibition of the $\mathrm{Na}+\mathrm{K}+$ ATPase pump, which exchanges intracellular sodium for extracellular potassium. Heparin has also been associated with hyperkalemia, and its mechanism involves a decrease in the production of aldosterone. The most relevant drugs associated with the increase of potassium are the $\beta 2$-adrenergic receptors blockers and the RAAS inhibitors, which prevent the production of renin and reduce the capacity of redistribution of potassium in the intracellular space ${ }^{10}$. Among the population without CKD, the incidence of hyperkalemia associated with the use of these drugs is highly variable, depending on the design of the study and the serum level of potassium considered high ${ }^{11}$. The increase of potassium ion has serious outcomes, such as arrhythmia, death, and discontinuation of drugs related to its elevation, which could lead to the worsening of the disease $^{11.12}$. A recent retrospective study demonstrated that patients with serum potassium level $>6.0 \mathrm{mmol} / \mathrm{L}$ had higher rates of hospitalization and death in comparison with individuals with serum potassium $\leq 5$ $\mathrm{mmol} / \mathrm{L}$. In addition, it demonstrated that the development of hyperkalemia was related to the use of RAAS inhibitors and the patients' initial GFR ${ }^{12}$.

In clinical practice, RAAS inhibitors are widely used in the treatment of CKD patients due to its cardiac and renal protective effect. In a recent review and meta-analysis, the use of RAAS inhibitors showed a kidney-protective effect in CKD patients with proteinuria; this is the first class of anti-hypertensive drugs for patients with this profile. However, the authors pointed out the risk of hyperkalemia ${ }^{13}$. Several clinical studies have shown the association of RAAS inhibitors with increased levels of potassium in CKD patients. In an observational study, the use of this class of medication was associated with an increase of $41 \%$ in the occurrence of hyperkalemia. Furthermore, the authors showed that individuals with CKD had a higher risk of increased potassium compared with patients with no renal injury ${ }^{14}$. The Renaal study followed patients with diabetic kidney disease in who used Losartan or a placebo. In this clinical trial, the 
group of individuals who used the Losartan had a greater risk of increased serum potassium than the placebo group ${ }^{15}$. In another study, patients who used the irbesartan had an incidence of $18.6 \%$ of hyperkalemia, while among patients who used the placebo, it was only $6 \%{ }^{16}$. Like in the general population without CKD, hyperkalemia is associated with a higher incidence of cardiovascular events and death in patients with renal injury ${ }^{17}$. It is worth noting that previous studies have demonstrated that the dual blockade with ACEI and ARB increased the incidence of hyperkalemia episodes, in addition to the occurrence of acute kidney injury ${ }^{18.19}$. Due to the risk of increased serum levels of potassium and, consequently, the unfavorable outcomes related to this event, the reduction or suspension of RAAS inhibitors is a common practice ${ }^{20}$. However, this practice can also cause undesirable events for patients. Epstein et al. demonstrated that patients who received a smaller dose or whose use of RAAS inhibitors was suspended after the occurrence of hyperkalemia presented a greater number of adverse events related to the progression of CKD, beginning of dialysis treatment, cardiovascular events, or death when compared to patients who maintained the maximum tolerated dose of these medications ${ }^{21}$. The balance between the risk of hyperkalemia and cardiac-renal protection that this class of medication presents makes it necessary to evaluate other therapeutic options to control the level of potassium.

\section{CLINICAL CONSEQUENCES}

Hyperkalemia can be classified according to the level of serum potassium into: mild $(5.5-6.0 \mathrm{mmol} / \mathrm{L})$, moderate $(6.0-6.5 \mathrm{mmol} / \mathrm{L})$, and severe $(>6.5 \mathrm{mmol} / \mathrm{L})$. Often, the clinical manifestations present as muscle weakness, paresthesia, paralysis, nausea, dyspnea, hypotension, cardiac arrhythmia, or cardiac arrest. One study showed that a serum potassium level $>6.0 \mathrm{mmol} / \mathrm{L}$ was associated with an increase of 30 times in the risk of mortality in one day; however, a level $>5.0 \mathrm{mmol} / \mathrm{L}$ was associated with long-term adverse events ${ }^{22}$. Thomsen et al. demonstrated that CKD patients who were not on dialysis and presented an episode of hyperkalemia during the study period had a higher risk of hospitalization due to ventricular arrhythmia, cardiac arrest, or other cardiac events ${ }^{8}$. Electrocardiographic changes that can be observed are the peaked T waves, prolonged PR interval, shorter QT interval, wider QRS complex, absence of P wave, ventricular fibrillation, or ventricular tachycardia. Additional laboratory tests are suggested, such as measurements of glucose, sodium, blood gas, renin, aldosterone, and cortisol, in addition to an electrocardiogram to assist in the choice of the best therapeutic option ${ }^{22}$.

\section{TREATMENT}

The management of hyperkalemia is divided into treatment for acute events and chronic control of serum potassium.

The treatment for acute elevations of potassium aims to antagonize the action of the ion in the cellular membrane and increase the potassium intake to the intracellular space. These measures provide a temporary reduction or removal of serum potassium. For that end, the therapeutic options are calcium gluconate, insulin, sodium bicarbonate, b-adrenergic antagonists, diuretics, and/or initiation or intensification of dialysis ${ }^{22}$. The focus of this review is not to provide a detailed description of the treatment for acute hyperkalemia.

In the treatment of non-severe hyperkalemia, for patients with CKD, dietary guidance should be carried out by a team of nutritionists to identify and replace foods rich in potassium and improve adherence to the dietary plan. It is worth mentioning that in patients with CKD, the inadequate restriction of vegetable, fruit, and liquid intake can cause or aggravate intestinal constipation, which results in increased intestinal absorption of potassium ${ }^{6.23}$.

Drugs associated with increased serum levels of potassium, such as beta-blockers, mineralocorticoids receptor antagonists, calcineurin, nonsteroidal anti-inflammatories, trimethoprim, and heparin should be adjusted or replaced in the occurrence of this complication $^{10}$. Special attention should be taken regarding RAAS inhibitors. As described above, these classes of drugs have a fundamental role in cardiac-renal protection, and their suspension should take into account the benefits of their use and the unfavorable outcomes that may occur after their suspension or reduction ${ }^{21}$.

Some patients, after the initial measures, still maintain a high level of potassium. For these, it is indicated to associate pharmacological approaches, such as the use of sodium bicarbonate and the introduction or increase of diuretics. The sodium bicarbonate dose varies between 3-5 grams per day and is indicated only in patients with metabolic acidosis. It 
is worth noting that this measure is poorly tolerated in patients with CKD patients in advanced stages due to the risk of increased blood pressure and fluid reten$\operatorname{tion}^{23}$. The prescription of diuretics should be made with caution and strict control to prevent hypovolemia, hypotension, decreased GFR, and, consequently, the recurrence of hyperkalemia ${ }^{24}$. In addition, exchange resins can be used (calcium polystyrene sulfonate; sodium polystyrene sulfonate; patiromer; sodium zirconium cyclosilicate).

Sodium polystyrene sulfonate is a resin that exchanges sodium for potassium, calcium, and ammonia and acts on the distal portion of the colon. The administration is via oral or rectal route, through laxatives and enemas, respectively. Clinical trials show that this resin is effective in the treatment of mild hyperkalemia in patients with CDK in the early stages. Doses between 60-80 grams lead to the fall of potassium serum levels by 0.9-1.7 mmol/L; however, it takes a long time for the medication to act. In addition to this delay of the therapeutic effect, the medication has frequent side effects, such as gastrointestinal intolerance, hypocalcemia, and magnesium deficiency. Also, to a lesser incidence, intestinal necrosis can occur. A recent study showed that patients with CKD and GFR $<30 \mathrm{~mL} / \mathrm{min}$ who used sodium polystyrene sulfonate had a higher risk of gastrointestinal events, including digestive bleeding. Thus, the use of this medication in CKD patients is questionable due to its uncertain efficacy, delayed effect, and the restricted use to mild hyperkalemia ${ }^{25}$.

Calcium polystyrene sulfonate is another resin that exchanges calcium for potassium. It also acts in the intestine and is administered via the oral route. The drug information leaflet makes reference to a rectal use by diluting it in sorbitol or methylcellulose. Its main side effect is constipation, but there have also been reported occurrences of hypercalcemia and hypercalciuria ${ }^{25}$. A Korean group followed 247 patients with GFR of $3015 \pm \mathrm{mL} / \mathrm{min} / 1.73 \mathrm{~m}^{2}$, for a period of 5-6 months and found a reduction in serum potassium levels ( $\geq 0.3 \mathrm{mmol} / \mathrm{L})$ in more than $70 \%$ of the participants who used the medication in a dose of 2.5-15 grams a day ${ }^{26}$. Wang et al. evaluated 58 patients on hemodialysis who presented hyperkalemia $\left({ }^{3} 5.5\right.$ $\mathrm{mmol} / \mathrm{L}$ ) for three weeks. In $61 \%$ of patients who used calcium polystyrene sulfonate, there was a decrease in the serum level of potassium $(<5.5 \mathrm{mmol} / \mathrm{L})^{27}$.

Similar to calcium polystyrene sulfonate, patiromer is a resin that acts in the colon, exchanging potassium for calcium. It is a new medication for the treatment of chronic hyperkalemia in CKD patients, and studies have demonstrated a good response to treatment. Like other ion exchange resins, the main side effect described is constipation. In addition to that, there have also been reports of mild hypomagnesemia ${ }^{5}$. The Amethyst-DN study evaluated 306 diabetic patients with CKD in stages 3 and 4, who used RAAS inhibitors for 52 weeks. The patients were stratified into mild and moderate hyperkalemia according to the serum level of potassium at the beginning of the study. The dose ranged from 4.2 to 16.8 grams twice a day, according to the initial potassium level. In the group classified as mild, the reduction of the serum level of potassium ranged between $0.35-0.55 \mathrm{mEq} / \mathrm{L}$. In patients of the moderate group, the reduction was $0.87-0.92 \mathrm{mEq} / \mathrm{L}$. The reduction in both groups was dose-dependent. In this study, they found a rate of $9.2 \%$ of worsening of CKD among patients treated with the medication. The authors cannot say whether this adverse event was secondary to the effect of drugs, an inherent progression of CKD, or due to the increased doses of the RAAS inhibiting drugs used in the treatment group ${ }^{28}$. Another large study evaluated patients with CKD, GFR between $15-60 \mathrm{~mL} / \mathrm{min} / 1.73 \mathrm{~m}^{2}$, serum levels of potassium between 5.1-6.6 $\mathrm{mmol} / \mathrm{L}$, and who were taking stable doses of all medications, including RAAS inhibitors and diuretics. All patients used patiromer for four weeks, with doses ranging between 4.2-8.4 grams twice a day, according to the initial potassium level. After this stage, the patients were divided into two groups, placebo and medication, for 8 more weeks of follow-up. In the patiromer group, there was a reduction in serum levels of potassium and an increased number of patients who were able to continue the use of RAAS inhibitors during the study period. In the placebo group, $60 \%$ of individuals had at least one episode of hyperkalemia during the second stage of the study ${ }^{29}$. A small study with patients on hemodialysis demonstrated that the use of patiromer decreased serum levels of potassium and phosphorus and increased potassium in the stool. The reported that no adverse effect was observed during the study period ${ }^{30}$.

Sodium zirconium cyclosilicate is a non-absorbable compound of zirconium silicate that acts as a selective exchanger of potassium and sodium for ammonia and hydrogen in the gastrointestinal tract, thus increasing the stool excretion of potassium. The recommended initial dose is 10 grams, three times a 
day. Normokalemia is achieved in a period of 24-48 hours, and it is recommended that the dose is reduced to maintain an optimal serum level of potassium ${ }^{25}$. A stage 3 study included 753 patients who had potassium levels between 5.0-6.5 mmol/L and divided them into placebo and medication groups. After 48 hours, there was a decrease in the level of potassium in the group that used sodium zirconium cyclosilicate, and the decrease rate was dose-dependent. In the maintenance stage, the potassium level remained within the range of normality in patients from the medication group. Diarrhea was the most common complication reported by the authors ${ }^{31}$. Kosiborod et al. evaluated patients with CKD, heart failure, and diabetes who presented hyperkalemia. The authors demonstrated that zirconium cyclosilicate was effective both in the rapid reduction, with an average time of two hours to decrease the level of potassium, and in the maintenance of normokalemia for up to four weeks in patients with various degrees of hyperkalemia. Normokalemia was achieved in $84 \%$ of patients after 24 hours, and in $98 \%$ after 48 hours of the onset of treatment ${ }^{32}$. In the recent Dialize study, the use of sodium zirconium cyclosilicate in patients undergoing hemodialysis treatment was able to maintain the serum level of potassium between $4.0-5.0 \mathrm{mmol} / \mathrm{L}$ in the period between dialysis, with few records of adverse events ${ }^{33}$.

Finally, in patients with pre-dialysis CKD, hyperkalemia resistant to pharmacological approaches have an indication to start renal replacement therapy ${ }^{6.22}$. For patients undergoing dialysis and with potassium levels constantly high, the use of dialysate with a low concentration ( 0 or $1 \mathrm{mmol} / \mathrm{L}$ ) of potassium is controversial since there have been reports of arrhythmia and sudden death after hemodialysis sessions with these concentrations. Studies suggest that these events could be related to the rapid fall in the extracellular concentration of the ion ${ }^{22.34}$. It is worth mentioning that these studies are all observational, and there have been no formal clinical trials. Possible solutions to this problem include prolonging the duration of the dialysis session, increasing the frequency of dialysis sessions, using new modalities of hemodialysis and/or potassium-binding resins ${ }^{22.34}$. Another obstacle to the control of hyperkalemia in CKD patients undergoing dialysis is the fluctuations in the serum level of potassium. These fluctuations may not be detected, since, usually, serum potassium is measured monthly, which would lead to the use of dialysate at an inadequate concentration of potassium in the dialysis infusion ${ }^{34}$.

\section{CONCLUSION}

Hyperkalemia is a metabolic complication often found in CKD patients and associated with severe outcomes. The rise of serum potassium is mainly related to the decrease in GFR and medications used to slow the progression of CKD and control associated diseases. The treatment of hyperkalemia includes dietary counseling and control, reduction or temporary suspension of medications, as well as the control of blood glucose levels in diabetic patients. In addition, sodium bicarbonate, diuretics, and potassium-binding resins can be used. Calcium polystyrene sulfonate is the only resin used in Brasil, and it has shown to be effective in the reduction of potassium, but it is poorly tolerated. Recent studies on resins not yet available in Brasil, i.e., patiromer and sodium zirconium cyclosilicate, show promising results for reducing serum potassium in CDK patients in all its stages.

\section{RESUMO}

A hiperpotassemia é um achado frequente em pacientes com doença renal crônica (DRC). Esta elevação do nível sérico de potássio está associada à diminuição da excreção renal do ín, assim como ao uso de medicações para retardar a progressão da DRC ou para controlar doenças associadas, como diabetes mellitus e insuficiência cardíaca. A hiperpotassemia aumenta o risco de episódios de arritmia cardíaca e morte súbita. Assim, o controle da elevação de potássio é essencial para a diminuição da taxa de mortalidade nessa população. O manejo da hiperpotassemia inclui, inicialmente, orientação de dietas com baixo teor de potássio e acompanhamento da aderência dos pacientes a esse procedimento. Também é importante conhecer as medicações em uso e a presença de comorbidades, a fim de orientar a redução de doses ou até mesmo a suspensão temporária de alguma das drogas relacionadas à retenção de potássio. E, finalmente, o uso de quelantes de potássio é indicado tanto em episódios agudos como nos casos de hiperpotassemia crônica.

PALAVRAS-CHAVE: Doença renal crônica. Hiperpotassemia. Inibidores do sistema renina-angiotensina-aldosterona. Poliestireno sulfonato de cálcio. Patiromer. Ciclossilicato de zircônio sódico. 


\section{REFERENCES}

1. Palmer BF, Clegg DJ. Physiology and pathophysiology of potassium homeostasis. Adv Physiol Educ. 2016;40(4):480-90.

2. Santos BF, Boim MA, Santos OF. Distúrbios do metabolismo do potássio. In: Ajzen H, Schor N, eds. Guia de nefrologia. $3^{\mathrm{a}}$ ed. Barueri: Manole; 2011. p.93-105.

3. Hayes J, Kalantar-Zadeh K, Lu JL, Turban S, Anderson JE, Kovesdy CP. Association of hypo- and hyperkalemia with disease progression and mortality in males with chronic kidney disease: the role of race. Nephron Clin Pract. 2012;120(1):c8-16.

4. Belmar Vega L, Galabia ER, Bada da Silva |, Bentanachs González M, Fernández Fresnedo G, Piñera Haces C, et al. Epidemiology of hyperkalemia in chronic kidney disease. Nefrologia. 2019;39(3):227-86.

5. Cowan AC, Gharib EG, Weir MA. Advances in the management of hyperkalemia in chronic kidney disease. Curr Opin Nephrol Hypertens. 2017;26(3):235-9.

6. Bianchi S, Aucella F, De Nicola L, Genovesi S, Paoletti E, Regolisti G. Management of hyperkalemia in patients with kidney disease: a position paper endorsed by the Italian Society of Nephrology. J Nephrol. 2019;32(4):499-516.

7. Caravaca-Fontán F, Valladares J, Díaz-Campillejo R, Barroso S, Luna E, Caravaca F. Association of hyperkalemia with clinical outcomes in advanced chronic kidney disease. Nefrologia. 2019;39(5):513-22.

8. Thomsen RW, Nicolaisen SK, Hasvold P, Sanchez RG, Pedersen L, Adelborg $K$, et al. Elevated potassium levels in patients with chronic kidney disease: occurrence, risk factors and clinical outcomes: a Danish population-based cohort study. Nephrol Dial Transplant. 2018;33(9):1610-20.

9. Kovesdy (P, Appel LJ, Grams ME, Gutekunst L, McCullough PA, Palmer BF, et al. Potassium homeostasis in health and disease: a scientific workshop cosponsored by the National Kidney Foundation and the American Society of Hypertension. Am J Kidney Dis. 2017;70(6):844-58.

10. Kovesdy CP. Management of hyperkalaemia in chronic kidney disease. Nat Rev Nephrol. 2014;10(11):653-62.

11. Tromp J, van der Meer P. Hyperkalaemia: aetiology, epidemiology, and clinical significance. Eur Heart J Suppl. 2019;21(Suppl A):A6-A11.

12. Horne L, Ashfaq A, MacLachlan S, Sinsakul M, Qin L, LoCasale R, et al. Epidemiology and health outcomes associated with hyperkalemia in a primary care setting in England. BMC Nephrol. 2019;20(1):85.

13. Mishima E, Haruna $Y$, Arima H. Renin-angiotensin system inhibitors in hypertensive adults with non-diabetic CKD with or without proteinuria: a systematic review and meta-analysis of randomized trials. Hypertens Res. 2019;42(4):469-82

14. Einhorn LM, Zhan M, Hsu VD, Walker LD, Moen MF, Seliger SL, et al. The frequency of hyperkalemia and its significance in chronic kidney disease. Arch Intern Med. 2009;169(12):1156-62.

15. Brenner BM, Cooper ME, de Zeeuw D, Keane WF, Mitch WE, Parving HH, et al; RENAAL Study Investigators. Effects of losartan on renal and cardiovascular outcomes in patients with type 2 diabetes and nephropathy. $\mathrm{N}$ Engl | Med. 2001;345(12):861-9.

16. Lewis EJ, Hunsicker LG, Clarke WR, Berl T, Pohi MA, Lewis JB, et al. Renoprotective effect of the angiotensin-receptor antagonist irbesartan in patients with nephropathy due to type 2 diabetes. N Engl J Med. 2001;345(12):851-60.

17. Georgianos PI, Agarwal R. Revisiting RAAS-blockade in CKD with newer potassium-binding drugs. Kidney Int. 2018;93(2):325-34
18. Mann JF, Schmieder RE, McQueen M, Dyal L, Schumacher H, Pogue J, et al; ONTARGET investigators. Renal outcomes with telmisartan, ramipril, or both, in people at high vascular risk (the ONTARGET study): a multicenter, randomized, double-blind, controlled trial. Lancet. 2008;372(9638):547-53.

19. Fried LF, Emanuele N, Zhang JH, Brophy M, Conner TA, Duckworth W, et al; VA NEPHRON-D Investigators. Combined angiotensin inhibition for the treatment of diabetic nephropathy. N Engl J Med. 2013;369(20):1892-903.

20. Jun M, Jardine MJ, Perkovic V, Pilard Q, Billot L, Rodgers A, et al. Hyperkalemia and renin-angiotensin aldosterone system inhibitor therapy in chronic kidney disease: a general practice-based, observational study. PLoS One. 2019;14(3):e02131192.

21. Epstein M. Hyperkalemia constitutes a constraint for implementing renin-angiotensin-aldosterone inhibition: the widening gap between mandated treatment guidelines and the real-world clinical arena. Kidney Int Suppl (2011). 2016;6(1):20-8.

22. Vijayakumar S, Butler|, Bakris GL. Barriers to guideline mandated renin-angiotensin inhibitor use: focus on hyperkalemia. Eur Heart J Suppl. 2019;21(Suppl A):A20-7.

23. Cupisti A, Brunori G, Di lorio BR, D'Alessandro C, Pasticci F, Cosola C, et al. Nutritional treatment of advanced CKD: twenty consensus statements. J Nephrol. 2018;31(4):457-73.

24. Khan YH, Sarriff A, Adnan AS, Khan AH, Mallhi TH. Chronic kidney disease, fluid overload and diuretics: a complicated triangle. PLoS One. 2016;11(7):e0159335.

25. Kim GH. Pharmacologic treatment of chronic hyperkalemia in patients with chronic kidney disease. Electrolyte Blood Press. 2018;17(1):1-6.

26. Yu MY, Yeo JH, Park JS, Lee CH, Kim GH. Long-term efficacy of oral calcium polystyrene sulfonate for hyperkalemia in CKD patients. PLoS One. 2017;12(3):e0173542.

27. Wang J, Lv MM, Zach O, Wang LY, Zhou MY, Song GR, et al. Calcium-polystyrene sulfonate decreases inter-dialytic hyperkalemia in patients undergoing maintenance hemodialysis: a prospective, randomized, crossover study. Ther Apher Dial. 2018;22(6):609-16.

28. Pitt $B$, Bakris GL, Weir MR, Freeman MW, Lainscak M, Mayo MR, et al. Long-term effects of patiromer for hyperkalaemia treatment in patients with mild heart failure and diabetic nephropathy on angiotensin-converting enzymes/angiotensin receptor blockers: results from AMETHYST-DN. ESC Heart Fail. 2018;5(4):592-602.

29. Weir MR, Bakris GL, Bushinsky DA, Mayo MR, Garza D, Stasiv Y, et al; OPAL-HK Investigators. Patiromer in patients with kidney disease and hyperkalemia receiving RAAS inhibitors. N Engl | Med. 2015;372(3):211-21.

30. Bushinsky DA, Rossignol P, Spiegel DM, Benton WW, Yuan |, Block GA, et al. Patiromer decreases serum potassium and phosphate levels in patients on hemodialysis. Am J Nephrol. 2016;44(5):404-10.

31. Packham DK, Rasmussen HS, Lavin PT, El-Shahawy MA, Roger SD, Block $G$, et al. Sodium zirconium cyclosilicate in hyperkalemia. N Eng | Med. 2015;372(3):222-31.

32. Kosiborod M, Rasmussen HS, Lavin P, Qunibi WY, Spinowitz B, Packham D, et al. Effect of sodium zirconium cyclosilicate on potassium lowering for 28 days among outpatients with hyperkalemia: the HARMONIZE randomized clinical trial. |AMA. 2014;312(21):2223-33.

33. Fishbane S, Ford M, Fukagawa M, McCafferty K, Rastogi A, Spinowitz B, et al. A phase $3 b$, randomized, double-blind, placebo-controlled study of sodium zirconium cyclosilicate for reducing the incidence of predialysis hyperkalemia. I Am Soc Nephrol. 2019;30(9):1723-33.

34. Abuelo |G. Treatment of severe hyperkalemia: confronting 4 fallacies. Kidney Int Rep. 2017;3(1):47-55. 